\title{
DIRECT MEASUREMENTS OF ARSENIC AND PHOSPHORUS EVOLUTION DURING CAP-ANNEALING OF GOLD-BASED METALLIZATIONS ON GaAs AND InP
}

\author{
A. Piotrowska, E. Kamińska, M. Guziewicz
}

Institute of Electron Technology, Al. Lotników 32/46, 02-668 Warszawa, Poland

\author{
R. Veresegyhazy, I. Mojzes and B. Pecz
}

Research Institute for Technical Physics, Hungarian Academy of Sciences 1325 Budapest, P.O. Box 76, Hungary

\begin{abstract}
Evolution of arsenic and phosphorus during heat treatment of unprotected and encapsulated $\mathrm{Au}, \mathrm{AuZn}$ and AuGeNi contacts on GaAs and InP has been examined and correlated with their ohmic behavior.
\end{abstract}

PACS numbers: $73.40 . \mathrm{Ns}$

The most widely used ohmic contacts to III-V semiconductors today are gold-based metallizations heat treated for a short time at temperatures in the range $400-500^{\circ} \mathrm{C}$. The contact schemes are designed to supply a suitable dopant and heat treatment is believed to drive it from metallization into the semiconductor so that tunneling may occur through the modified metal-semiconductor Schottky barrier. The metallurgy of these contacts, however, has been found to be complex chemically and typical processing leads to highly nonuniform microstructure of the interfacial region [1]. Moreover, semiconductor anion $(\mathrm{As}, \mathrm{P})$ was found to rapidly evaporate through the metallic layer during ohmic contact formation causing deep disruption of underlying semiconductor $[2,3]$. In spite of considerable work in this field the understanding of the basic processes which determine the ohmic behavior of these contacts is still far from satisfactory.

As a part of our ongoing studies on interfacial reactions in gold-based metallizations, cap-annealed $\mathrm{AuZn} / p$-GaAs ohmic contacts with improved surface and interface morphology have been demonstrated [4]. It has been suggested that this has been achieved owing to the suppression of the loss of arsenic in "closed system" 
and that the usually observed substantial decomposition of GaAs is not a necessary condition for creating ohmic contact. In this work, we have directly examined the evolution of volatile component of III-V semiconductor during contact reaction of pure $\mathrm{Au}, \mathrm{AuZn}$ (being the conventional contact for $p$-type semiconductors) and AuGeNi metallization (commonly used contact for $n$-type materials) with (100)GaAs and (100)InP LEC-grown substrates. $200 \mathrm{~nm}$ thick, RF-magnetron sputtered $\mathrm{SiO}_{2}$ and $\mathrm{Si}_{3} \mathrm{~N}_{4}$ layers and $\mathrm{RF}$ reactively sputtered TiN films were used for cap-annealings. Contacts were heat treated in vacuum, with a heating rate of $100^{\circ} \mathrm{C} / \mathrm{min}$. The evolution of arsenic and phosphorus was monitored with a computer controlled quadrupole mass spectrometer. The results of Evolved Gas Analysis (EGA) have been correlated with the measurements of the specific contact resistance $r_{\mathrm{c}}$. A schematic diagram of the system used to monitor evaporative losses is shown in Fig. 1. A further account of the preparation of the samples and measurement procedures may be found in related publications [4-8].

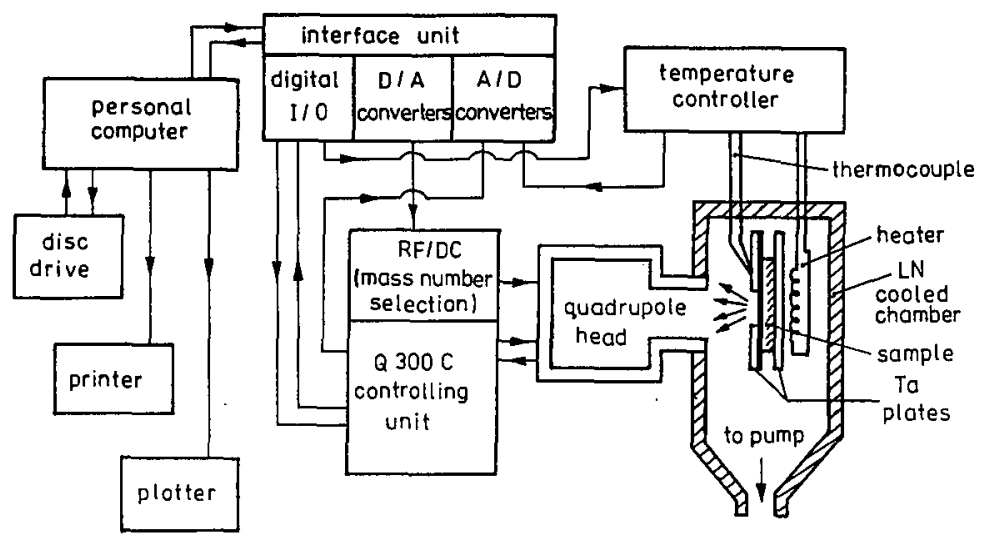

Fig. 1. The experimental setup for Evolved Gas Analysis.

EGA measurements have shown that in all cases the dominating evolved species follow the order $\mathrm{As}_{4}>\mathrm{As}_{2}$ and $\mathrm{P}_{4}>\mathrm{P}_{2}$, consistently for uncapped and cap-annealed contacts. The yield of $\mathrm{As}_{4}$ and $\mathrm{P}_{4}$ molecules during continuous heating of unprotected and $\mathrm{SiO}_{2}$ capped $\mathrm{Au}, \mathrm{AuZn}$ and $\mathrm{AuGeNi}$ contacts to GaAs and InP is shown in Fig. 2.

For contacts annealed without $\mathrm{SiO}_{2}$ cover the yield versus temperature curves exhibit a multiple peak structure, characteristic of the metal and semiconductor system. The maxima of evaporative losses correspond well to the sequential appearance of $\mathrm{Au}-\mathrm{Ga}$ and $\mathrm{Au}-\mathrm{In}$ alloys of the composition having increasing content of group-III element for higher annealing temperature (as determined previously in these contacts by XRD and SIMS). Correlation of evaporative losses together with the measurements of $\mathrm{I}-\mathrm{V}$ characteristics of $\mathrm{AuZn}$ and AuGeNi contacts suggests that the change from rectifying to ohmic behavior occurs at temperatures slightly below the first $\mathrm{As}_{4}$ and $\mathrm{P}_{4}$ peak appearance. The U-like dependence $r_{\mathrm{c}}$ reaches minimum at temperatures at which $A$ s and $P$ release is high $\left(400-420^{\circ} \mathrm{C}\right)$. 

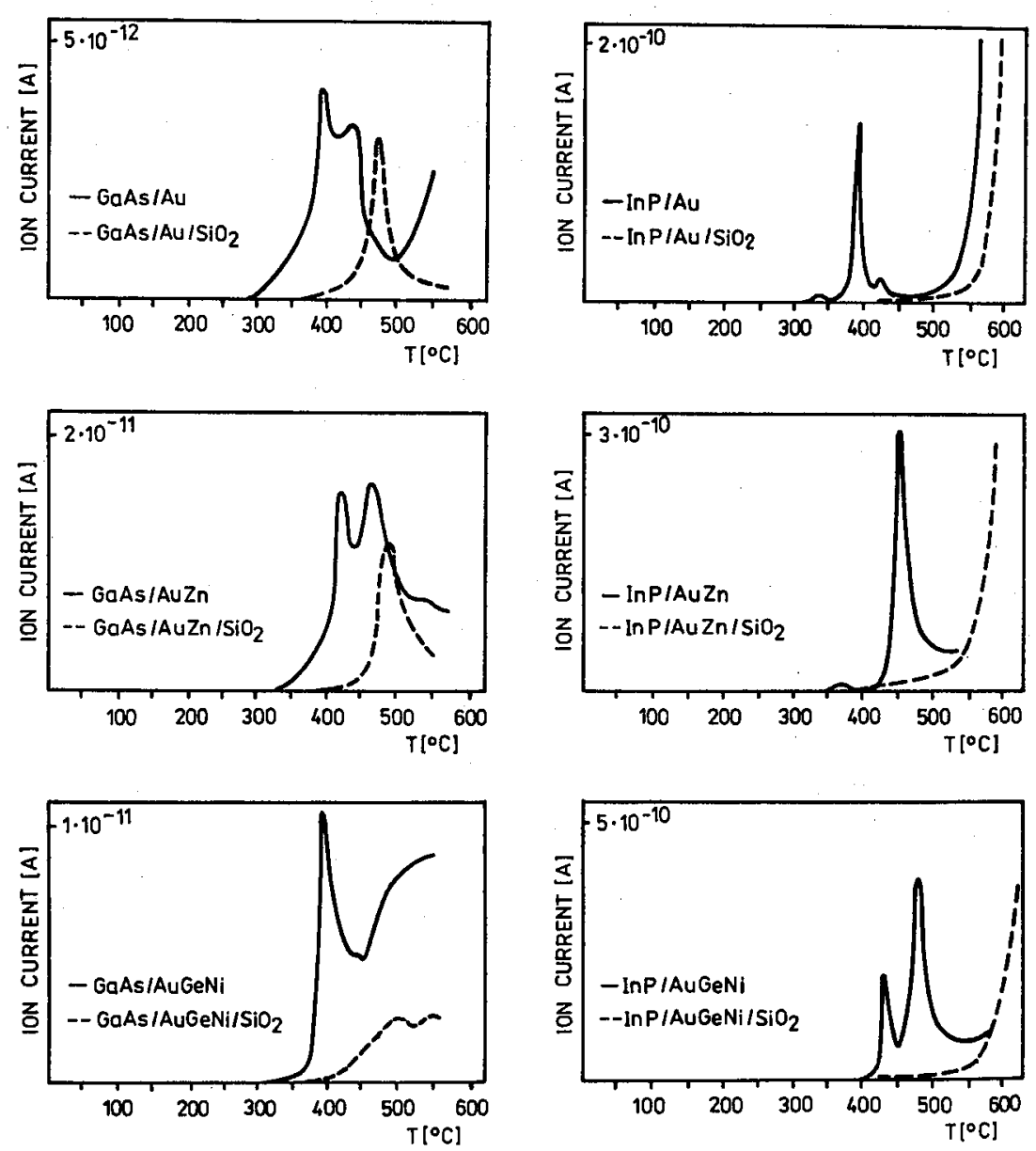

Fig. 2. EGA of $\mathrm{As}_{4}$ and $\mathrm{P}_{4}$ ions evolution during annealing of unprotected and $\mathrm{SiO}_{2}$-capped $\mathrm{Au}, \mathrm{AuZn}$ and $\mathrm{AuGeNi}$ contacts to $\mathrm{GaAs}$ and $\mathrm{InP}$.

Figure 2 proves the ability of $\mathrm{SiO}_{2}$ cap to reduce evaporative losses. The Ast and $\mathrm{P}_{4}$ evaporation peaks are suppressed or shifted by at least $100^{\circ} \mathrm{C}$ to higher temperatures. Simultaneously ohmic contacts with lower $r_{\mathrm{c}}$ have been obtained. In this case, the dependence $r_{\mathrm{c}}(T)$ exhibits broad minimum at temperatures far below the release of $A s$ and $P\left(r_{c}\right.$ increases less than $2 \%$ when the annealing temperature diverge by $50^{\circ} \mathrm{C}$ from the optimum one).

All examined annealing caps have been effective in suppressing the loss of volatile component of semiconductor at temperatures required for the formation of ohmic contacts.

The above results strongly support our previous suggestion that substantial decomposition of GaAs and InP during contact annealing is a by-product of contact reaction rather than necessary condition for creating ohmic contact. 
We think that ohmic contact formation requires adequate balance between the generation of semiconductor vacancies and the supply of doping species at the metal-semiconductor interface, without, however the creation of a highly doped layer of appreciable thickness. As for the application perspective, TiN capping layer can be superior to the dielectric ones from the standpoint of its compatibility with the whole metallization layout.

\section{References}

[1] G.Y. Robinson, in Physics and Chemistry of III-V Compound Semiconductor Interfaces, Ed. C.W. Wilmsen, Plenum, New York 1985, p. 73.

[2] T. Sebestyen, M. Menyhard, D. Szigethy, Electron. Lett. 12, 96 (1976).

[3] E. Kinsbron, P.K. Gallagher, A.T. English, Solid-State Electron. 22, 517 (1979).

[4] A.J. Barcz, E. Kamińska, A. Piotrowska, Thin Solid Films 149, 251 (1987).

[5] A. Piotrowska, E. Kamińska, A. Barcz, J. Adamczewska, A. Turos, Thin Solid Films 130, 231 (1985).

[6] E. Kamińska, A. Piotrowska, A. Barcz, J. Adamczewska, A. Turos, Solid St. Electron. 29, 279 (1986).

[7] R. Veresegyhazy, I. Mojzes, B. Kovacs, B. Pecz, in Proc. 11th Int. Mass Spectrometry Conf., Advances in Mass Spectrometry, Vol. 11 (1989).

[8] B. Pecz, R. Veresegyhazy, E. Jaroli, E. Zsoldos, I. Mojzes, Yugoslav-Austrian-Hungarian IV Joint Vacuum Conf., Portoroz (Yugoslavia) 1988. 